\title{
Insulin Does Not Augment In Vitro Tumor Growth Under A Hyperglycemia-Mimicking Milieu And In A Calorie Restriction-Resembling Manner
}

Tao Liao ${ }^{1}$, Xiao-Hui Li², Yan-Ping Chen ${ }^{1}$, Li-Li Tan ${ }^{1}$, Ji-Da Zhang ${ }^{3}$, Xin-An Huang ${ }^{1}$, Qin $\mathrm{Xu}^{1}$, Sui-Qing Huang ${ }^{4}$, Chang-Qing $\mathrm{Li}^{1 *}$, Qing-Ping Zeng ${ }^{1 *}$

${ }^{1}$ Tropical Medicine Institute, Guangzhou University of Chinese Medicine, Guangzhou 510405, China.

${ }^{2}$ College of Chinese Medicine, Guangzhou University of Chinese Medicine, Guangzhou 510405, China.

${ }^{3}$ College of Basic Medical Sciences, Zhejiang Chinese Medical University, Hangzhou 310053, China

${ }^{4}$ Basic Medical Science College, Guangzhou University of Chinese Medicine, Guangzhou 510405, China.

* E-mail

qpzeng@163.com

1106923438@qq.com 


\section{Abstract}

Background: Whether insulin enhances or represses tumor cell proliferation remains debating and inconclusive although epidemiological data indicated insulin use raises a risk of cancer incidence in patients with diabetes mellitus (DM).

Methodology/Principle Findings: We cultured rat pituitary adenoma cells in a high-glucose medium to simulate hyperglycemia occurring in DM patients. Upon incubation with or without insulin, repressed tumor cell proliferation and downregulated tumor marker expression occur accompanying with mitigated oxidative stress and compromised apoptosis. Mechanistically, insulin resistance-abrogated glucose uptake was suggested to create an intracellular low-glucose milieu, leading to cellular starvation resembling calorie restriction (CR). While downregulation of insulin-like growth factor 1 (IGF-1) occurring in CR was validated, oncogene downregulation and tumor suppressor gene upregulation seen in $\mathrm{CR}$ was also replicated by NOS2 knockdown.

Conclusions/Significance: Cellular starvation can exert CR-like anti-tumor effects regardless of insulin presence or absence.

\section{Introduction}

Until 2015, approximately 415 million adults aged 20-79 have been estimated to live with diabetes mellitus (DM) worldwide, including 193 million who are undiagnosed [1]. From 2012-2015, 1.5 to 5.0 million deaths annually resulted from DM [2]. As an encouraging news for combating DM, the long-acting human insulin analogue insulin glargine with a relatively durable (18-26 h) hypoglycemic effect has been developed and widely marketed with a trade name of Lantus or Toujeo [3]. However, this improved human insulin derivative unfortunately has irritated a public concern of safety because the independent epidemiological investigations have associated a raised cancer risk with insulin use in DM patients [4-7]. Although the latest conclusions from meta-analyses of case reports has excluded a likelihood of insulin glargine in tumor induction [8,9], evidence supporting its potential risk in promoting cancer onset is continuing to emerge from the recent clinical surveys [10,11].

It seems a tremendous challenge to figure out why the previous epidemiological reports regarding insulin glargine's effects on tumorigenesis is inconsistent before the bona fide etiological initiators of DM and cancer become identified [12], but it should 
be possible to clarify whether insulin enhances or represses tumor growth in DM patients. For this purpose, we assessed a putative correlation of insulin use with tumor growth in the in vitro cultured rat pituitary adenoma cell line GH3. Pituitary adenomas are common intracranial tumors accounting for $25 \%$ of brain tumors, which are generally benign but can cause significant morbidity via deregulated hormone production. Current strategies of therapy include medication, surgery, and radiotherapy [13]. However, there remains a substantial proportion of patients whose tumors are refractory to surgical and medical therapies. Therefore, other medical options attacking the tractable pituitary adenomas are needed urgently by targeting their aberrant metabolic patterns such as enhanced PI3K-Akt-mTOR signaling [14, $15]$.

To preliminarily investigate whether insulin would enhance in vitro pituitary adenoma proliferation, we cultured $\mathrm{GH} 3$ cells in a high-glucose $(17.49 \mathrm{mM})$ or a higher-glucose $(30 \mathrm{mM})$ medium supplemented with or without insulin $\left(10^{-9}-10^{-7} \mathrm{M}\right)$. The glucose concentrations of $17.49 \mathrm{mM}$ and $30 \mathrm{mM}$ were chosen to mimic hyperglycemia seen in DM patients because $25 \mathrm{mM}$ glucose in the medium is equal to hyperglycemia, while $5.5 \mathrm{mM}$ glucose in the medium corresponds to normoglycemia [16]. It was previously indicated that under a sustained hyperglycemic condition, glucose uptake is impeded due to downregulation of glucose transporter 1 (GLUT1) [16], resembling insulin resistance seen in type 2 diabetes mellitus (T2DM). In practical, 10, 15, and $25 \mathrm{mM}$ glucose were used to induce insulin resistance in 3T3-L1 adipocytes [17]. Similarly, $10^{-7} \mathrm{M}$ insulin was also used to induce insulin resistance in HepG2 hepatoma cells [18], so we chose the insulin dose range from $10^{-9} \mathrm{M}$ to $10^{-7}$ M.

Insulin resistance would prohibit glucose uptake and hence create an intracellular low glucose milieu, so-called cellular starvation, which mimics calorie restriction (CR) to reverse the process of cancer progression, invasion, and metastasis [19, 20]. Because CR was validated to block NF-kB responsive NOS2 that encodes inducible nitric oxide synthase (iNOS) [21], we exploited NOS2 knockdown to reveal a possible mechanism underlying cellular starvation exerting anti-tumor effects in a CR-like manner. If this is true, it should predicted that insulin resistance-induced hyperglycemia might decrease rather than increase the risk of cancer progression in T2DM-combined cancer patients upon insulin administration. Indeed, a conclusion that insulin does not enhance tumor cell proliferation in a high-glucose circumstance 
has been drawn from the present study.

Nevertheless, insulin use in type 1 diabetes mellitus (T1DM) patients with insulin deficiency or pro-diabetes individuals with insulin sensitivity might increase the cancer risk because of an intracellular high glucose milieu, which can activate the PI3K-Akt-mTOR signaling pathway to promote cell division $[19,20]$. It should be essential, therefore, to accurately evaluate the cancer risk upon insulin use by distinguishing insulin resistance from insulin sensitivity. Our prospective anticipation regarding a causal link of insulin use to cancer incidence and progression merits further in vivo studies.

\section{Results}

\section{Insulin-combined high-level glucose represses tumor cell proliferation and diminishes growth hormone secretion}

Upon incubation with $10^{-7} \mathrm{M}$ insulin for 24 or $48 \mathrm{~h}$, GH3 cells exhibit a slightly faster growth rate than untreated GH3 cells albeit without statistical significance. However, when measured on $72 \mathrm{~h}, 10^{-7} \mathrm{M}$ insulin remarkably delays $\mathrm{GH} 3$ cell growth with significant difference from untreated GH3 cells (Figure 1A). After incubation with $10^{-8} \mathrm{M}$ insulin for 24,48 , or $72 \mathrm{~h}$, GH3 cells grow slower than untreated GH3 cells though without statistical significance (Figure 1B). The similar situation occurs in GH3 cells incubated with $10^{-9} \mathrm{M}$ insulin for 24,48 , or $72 \mathrm{~h}$ (Figure 1C). These results unraveled $10^{-7} \mathrm{M}$ insulin for $72 \mathrm{~h}$ incubation significantly represses tumor cell proliferation, and $10^{-8}$ or $10^{-9} \mathrm{M}$ insulin does not enhance tumor cell proliferation.

To reveal the implication of insulin in modulation of growth hormone $(\mathrm{GH})$, we quantified its expressed mRNA and protein levels by quantitative polymerase chain reaction (qPCR) and Western blotting (WB). Consequently, it was clearly that untreated GH3 cells show a significantly higher level of $G H$ mRNA than $10^{-9} \mathrm{M}$ insulin-treated GH3 cells as measured on $24 \mathrm{~h}$ and $72 \mathrm{~h}$ (Figure 1D). Similarly, untreated GH3 cells also display a significantly higher level of GH than $10^{-9} \mathrm{M}$ insulin-treated GH3 cells when tested on $24 \mathrm{~h}$ and $72 \mathrm{~h}$ (Figure 1E). Additionally, insulin remarkably downregulates $G H$ mRNA and $\mathrm{GH}$ in $10^{-9} \mathrm{M}$ for $72 \mathrm{~h}$. These results of declined $\mathrm{GH}$ expression and diminished $\mathrm{GH}$ secretion might imply inhibitory tumor proliferation. 
A

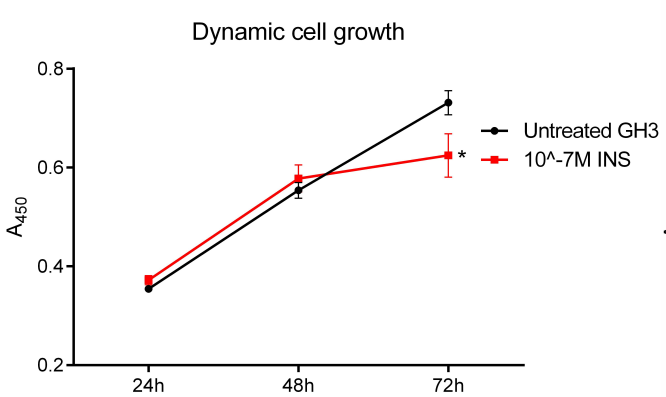

B

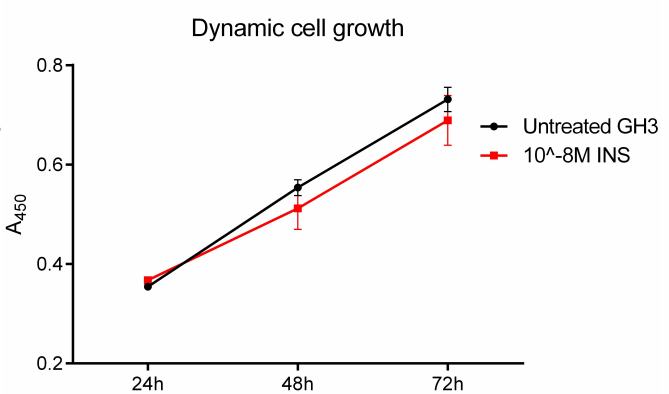

C

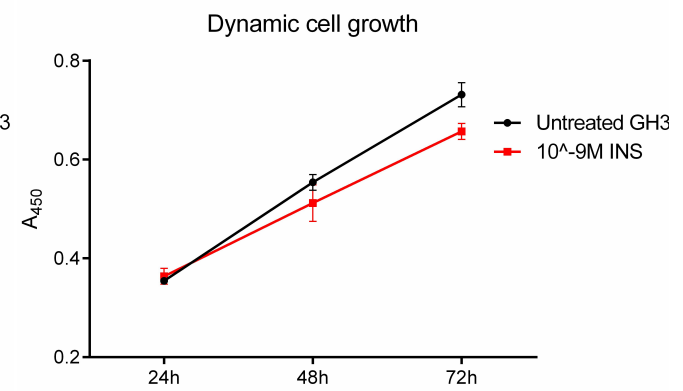

D

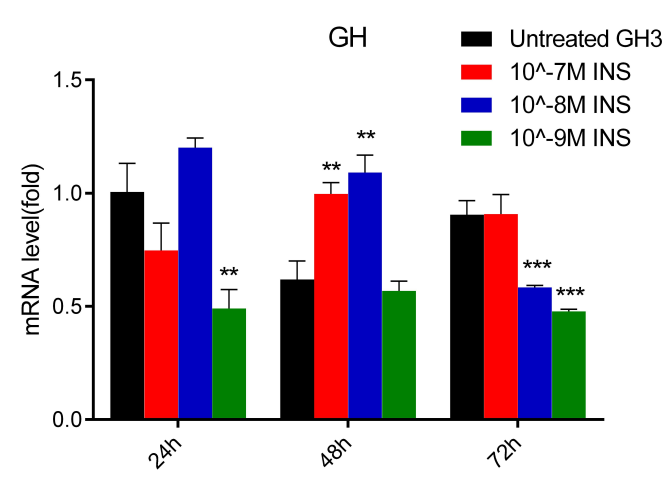

E

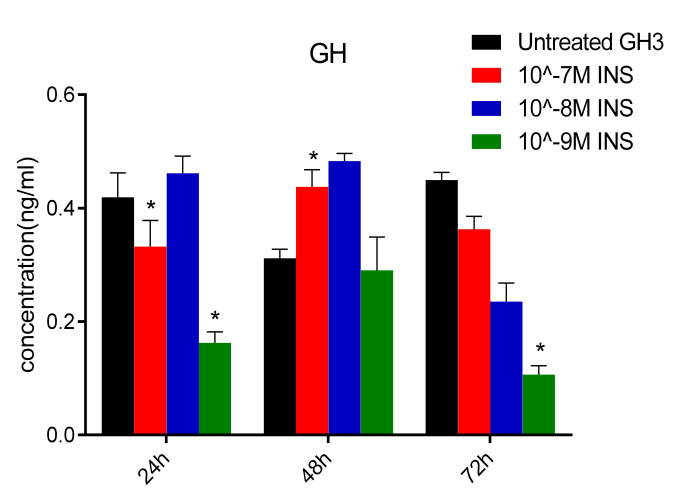

Figure 1. Effects of exogenous insulin on tumor cell proliferation and hormone secretion in $\mathrm{GH} 3$ cells grown in a high-glucose medium. (A-C) $\mathrm{A}_{450}$ values representing cell growth and measured by cell counting kit 8 (CCK-8) after incubation for 24,48 , or $72 \mathrm{~h}$ in $10^{-7}(\mathrm{~A}), 10^{-8}(\mathrm{~B})$, or $10^{-9} \mathrm{M}(\mathrm{C})$ insulin. (D) Fold changes of $G H$ mRNA. (E) Concentrations of GH. Glucose concentration is $17.49 \mathrm{mM}$. Insulin dose is $10^{-7}, 10^{-8}$, or $10^{-9} \mathrm{M}$, and incubation duration is 24,48 , or $72 \mathrm{~h}$. INS: insulin. *: Significant difference from untreated GH3 cells $(p<0.05, n=10)$. **: Very significant difference from untreated GH3 cells $(p<0.01)$. ***: Very very significant difference from untreated GH3 cells $(p<0.001, n=10)$.

\section{Insulin-combined high-level glucose downregulates tumor marker gene expression}

To more accurately evaluate the effect of insulin on tumor growth, we quantified the common tumor markers, cyclin 1 (CD1) and alpha fetoprotein (AFP), in the insulin-treated GH3 cells by qPCR and WB. After incubation with $10^{-7}, 10^{-8}$, or $10^{-9} \mathrm{M}$ insulin for 24,48 , or $72 \mathrm{~h}$, GH3 cells show much lower levels of $C D 1$ mRNA (Figure $2 \mathrm{~A}$ ) and $A F P$ mRNA (Figure $2 \mathrm{~B}$ ) than untreated GH3 cells with very significant statistical difference. From WB results illustrated in Figure 2C-2E, it was also noticeable that $\mathrm{CD} 1$ and $\mathrm{AFP}$ levels in $10^{-7}, 10^{-8}$, or $10^{-9} \mathrm{M}$ insulin-treated $\mathrm{GH} 3$ cells are almost lower than those in untreated GH3 cells after incubation for 24, 48, or $72 \mathrm{~h}$. These results indicated downregulation of tumor marker expression is concomitant 
with suppression of tumor cell proliferation.

A

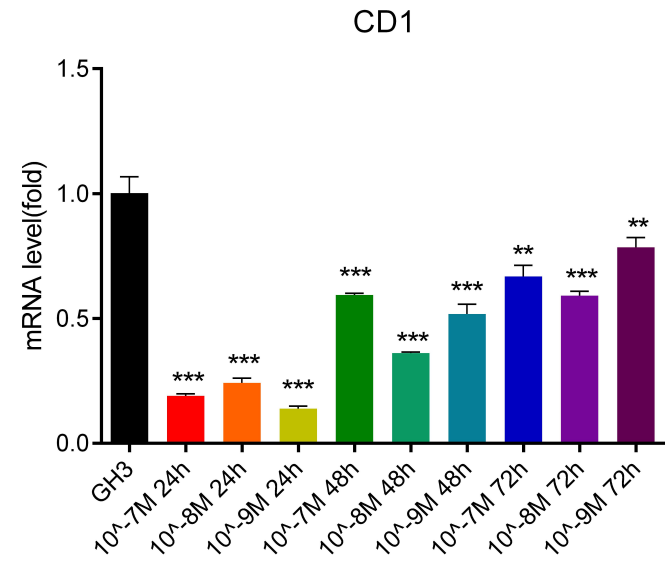

B

AFP

C

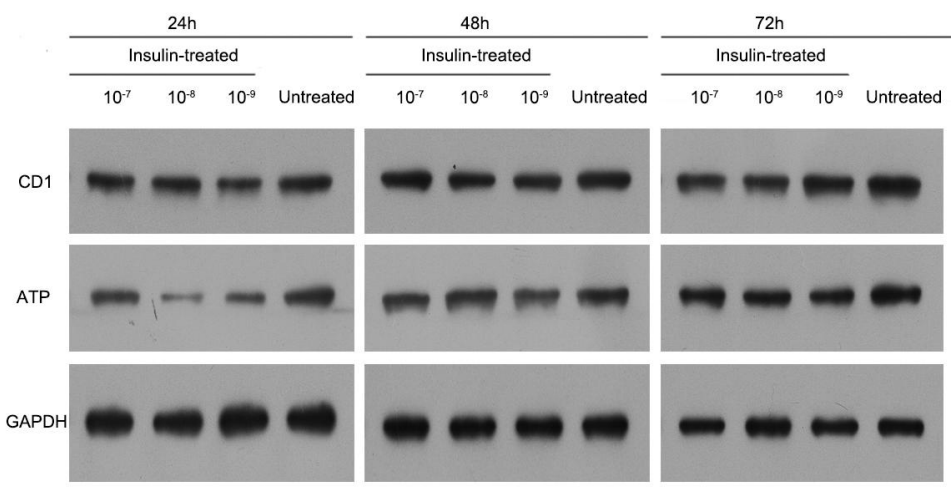

Figure 2. Effects of exogenous insulin on tumor marker gene expression in GH3 cells grown in a high-glucose medium. (A) Fold changes of $C D 1$ mRNA. (B) Fold changes of $A F P$ mRNA. (C-E) Concentrations of CD1 and AFP. Glucose concentration is $17.49 \mathrm{mM}$. Insulin dose is $10^{-7}, 10^{-8}$, or $10^{-9} \mathrm{M}$, and incubation duration is 24,48 , or $72 \mathrm{~h}$. **: Very significant difference from untreated GH3 cells $(p<0.01, n=10)$. ***: Very very significant difference from untreated GH3 cells $(p<0.001, n=10)$.

It was more remarkable from a comparison of relative gray-scale values estimated from CD1/glyceraldehyde-3-phosphate dehydrogenase (GAPDH) or AFP/GAPDH, in which $10^{-9} \mathrm{M}$ insulin-treated GH3 cells for 24 h show the lowest CD1/GAPDH ratio, and $10^{-8} \mathrm{M}$ insulin-treated GH3 cells for $24 \mathrm{~h}$ exhibit the lowest AFP/GAPDH ratio (Table 1). These results indicated insulin in the doses of $10^{-7}, 10^{-8}$, or $10^{-9} \mathrm{M}$ and during incubation for 24,48 , or $72 \mathrm{~h}$ declines CD1 and AFP levels at different extents. Although AFP was considered to be mainly synthesized in hepatic cells, it is also expressed in GH3 cells with an almost comparative level to CD1, perhaps representing a non-specific expression pattern. 
Table 1 Comparison of CD1/GAPDH and AFP/GAPDH derived from the gray-scale values of WB bands in untreated GH3 cells and $10^{-7}, 10^{-8}$, or $10^{-9} \mathrm{M}$ insulin-treated GH3 cells for 24, 48, or $72 \mathrm{~h}$

\begin{tabular}{cccccc}
\hline $\begin{array}{c}\text { Incubation } \\
\text { time }\end{array}$ & $\begin{array}{c}\text { Target protein/ } \\
\text { Reference protein }\end{array}$ & $\begin{array}{c}10^{-7} \mathrm{M} \text { insulin- } \\
\text { treated GH3 }\end{array}$ & $\begin{array}{c}10^{-8} \mathrm{M} \text { insulin- } \\
\text { treated GH3 }\end{array}$ & $\begin{array}{c}10^{-9} \mathrm{M} \text { insulin- } \\
\text { treated GH3 }\end{array}$ & $\begin{array}{c}\text { Untreated } \\
\text { 24h }\end{array}$ \\
& $\mathrm{CD} 1 / \mathrm{GAPDH}$ & 0.64 & 0.58 & 0.35 & 0.61 \\
& $\mathrm{AFP} / \mathrm{GAPDH}$ & 0.35 & 0.05 & 0.14 & 0.50 \\
\hline $48 \mathrm{~h}$ & $\mathrm{CD} 1 / \mathrm{GAPDH}$ & 0.82 & 0.68 & 0.64 & 0.81 \\
& $\mathrm{AFP} / \mathrm{GAPDH}$ & 0.37 & 0.52 & 0.33 & 0.59 \\
\hline $72 \mathrm{~h}$ & $\mathrm{CD} 1 / \mathrm{GAPDH}$ & 0.74 & 0.65 & 1.12 & 1.31 \\
& $\mathrm{AFP} / \mathrm{GAPDH}$ & 0.85 & 0.78 & 0.80 & 1.06 \\
\hline
\end{tabular}

\section{High-level glucose without insulin also downregulates tumor marker gene expression on the translational level}

To simulate hyperglycemia occurring in DM patients, we employed a higherglucose $(30 \mathrm{mM})$ and insulin-free medium during GH3 cell culture. After incubation for 24,48 , or $72 \mathrm{~h}$, it was obviously that $C D 1 \mathrm{mRNA}$ levels in $30 \mathrm{mM}$ glucose-cultured GH3 cells are significantly higher as tested on 24 and $72 \mathrm{~h}$, but equal to those in $17.49 \mathrm{mM}$-cultured GH3 cells on $48 \mathrm{~h}$ (Figure 3A), whereas AFP mRNA levels are significantly higher as tested on 48 and $72 \mathrm{~h}$, but equal to those in 17.49 mM-cultured GH3 cells on $24 \mathrm{~h}$ (Figure 3B). Nevertheless, CD1 and AFP protein levels in $30 \mathrm{mM}$ glucose-cultured GH3 cells are generally equal to those in 17.49 mM-cultured GH3 cells, only except for $72 \mathrm{~h}$ (Figure 3C). As tested on $72 \mathrm{~h}$, for example, CD1/GAPDH and AFP/GAPDH is 0.41 and 0.18 in $30 \mathrm{mM}$ glucose-cultured GH3 cells, whereas it is 0.05 and 0.13 in $17.49 \mathrm{mM}$ glucose-cultured GH3 cells ( and Table 2). These transcriptional accelerated but translationally inhibited expression of $C D 1$ and $A F P$ might be resulted from the general formation of a cellular starvation state because glucose uptake is proceeded slowly without insulin action.

Table 2 Comparison of CD1/GAPDH and AFP/GAPDH derived from the gray-scale values of WB bands in 17.49 mM glucose-cultured GH3 cells and $30 \mathrm{mM}$ glucose-cultured GH3 cells for 24, 48, or 72 h

\begin{tabular}{ccccccc}
\hline Target protein/ & \multicolumn{3}{c}{$17.49 \mathrm{mM}$ glucose-cultured GH3 } & \multicolumn{3}{c}{$30 \mathrm{mM}$ glucose-cultured GH3 } \\
\cline { 2 - 7 } Reference protein & $24 \mathrm{~h}$ & $48 \mathrm{~h}$ & $72 \mathrm{~h}$ & $24 \mathrm{~h}$ & $48 \mathrm{~h}$ & $72 \mathrm{~h}$ \\
\hline CD1/GAPDH & 0.34 & 0.27 & 0.05 & 0.25 & 0.24 & 0.41 \\
AFP/GAPDH & 0.45 & 0.25 & 0.13 & 0.09 & 0.17 & 0.18 \\
\hline
\end{tabular}




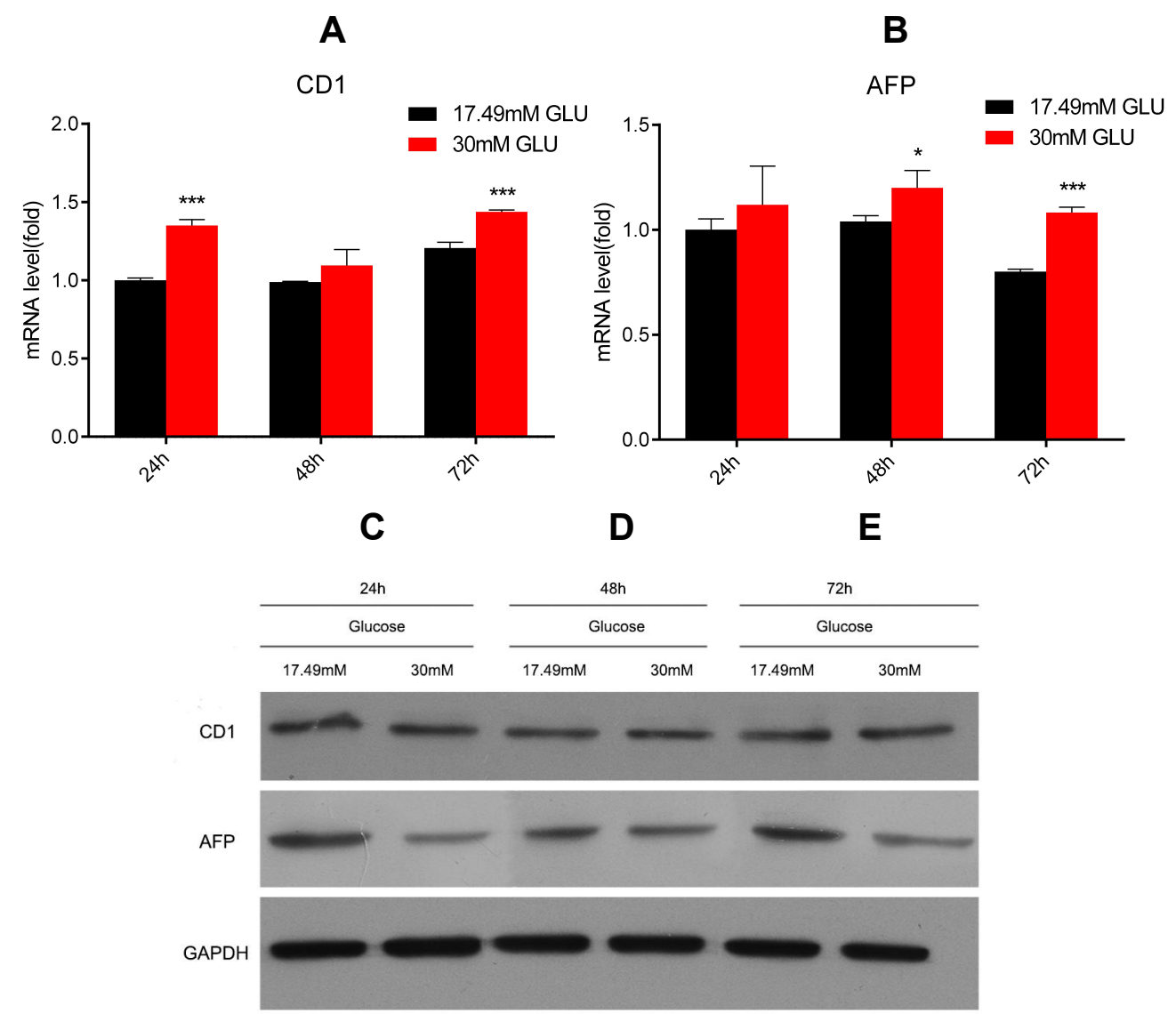

Figure 3. Effects of high-glucose on tumor marker gene expression in GH3 cells grown in insulin-free medium. (A) Fold changes of CD1 mRNA. (B) Fold changes of AFP mRNA. (C-E) Concentrations of CD1 and AFP. Glucose concentration is $17.49 \mathrm{mM}$ or $30 \mathrm{mM}$. Incubation duration is 24,48 , or $72 \mathrm{~h}$. GLU: glucose. *: Significant difference from untreated GH3 cells $(p<0.05, n=10)$. ***: Very very significant difference from untreated GH3 cells $(p<0.001, n=10)$.

\section{High-level glucose with or without insulin compromises ROS burst}

To explore whether insulin might exert anti-oxidative roles, we determined the ROS levels in GH3 cells upon incubation with $10^{-7}, 10^{-8}$, or $10^{-9} \mathrm{M}$ insulin for 24,48 , or 72 h. From Figure 4A-4C, it was clearly seen that ROS levels in insulin-treated GH3 cells are much lower than those in untreated GH3 cells, in which the higher the insulin doses, the lower the ROS levels. For example, the fluorescence strengths representing ROS levels in $10^{-7}, 10^{-8}$, or $10^{-9} \mathrm{M}$ insulin-treated GH3 cells for $24 \mathrm{~h}$ are $59.3 \%$, $81.0 \%$, or $82.3 \%$, whereas those in untreated GH3 cells were $96.0 \%$, suggesting insulin might attenuate ROS burst or scavenge ROS already generated.

When incubation of GH3 cells with $30 \mathrm{mM}$ glucose for 24 , 48, or $72 \mathrm{~h}$, ROS levels (Figure 4D-4F) are also unchanged or lower as compared with $17.49 \mathrm{mM}$ glucose-cultured GH3 cells. For example, ROS levels are $21.1 \%$ and $29.9 \%$ in $30 \mathrm{mM}$ glucose-cultured GH3 cells and $17.49 \mathrm{mM}$ glucose-cultured GH3 cells after 
incubation for $72 \mathrm{~h}$, respectively. These results suggested cellular starvation might compromise ROS burst.

A
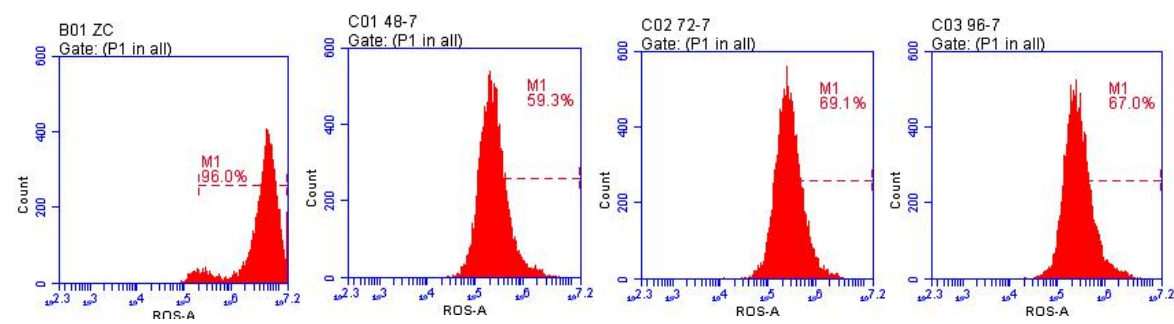

B
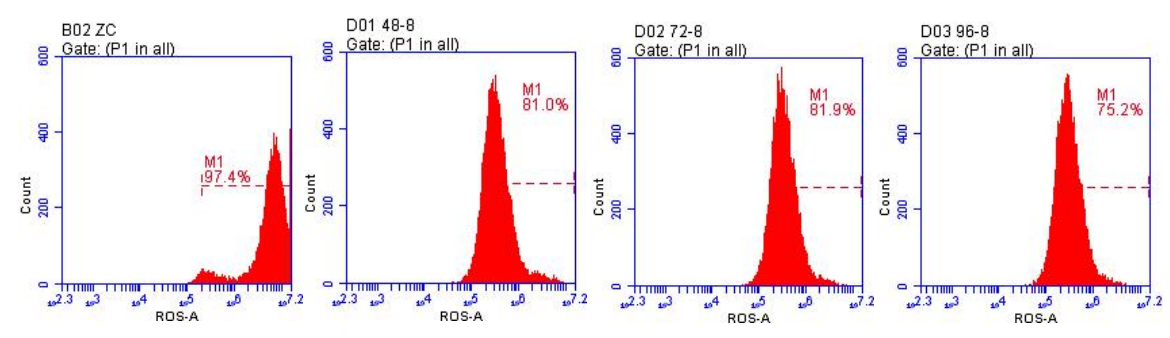

C

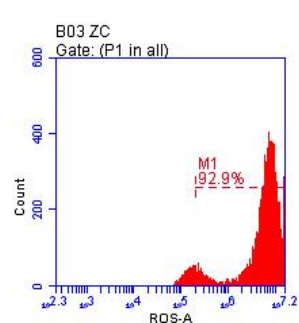

D

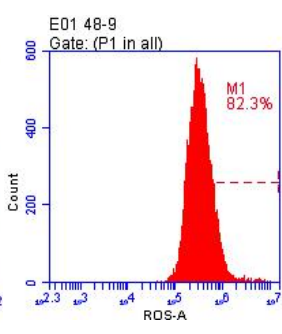

E

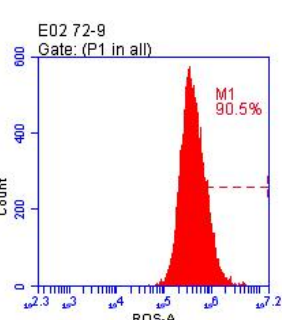

E

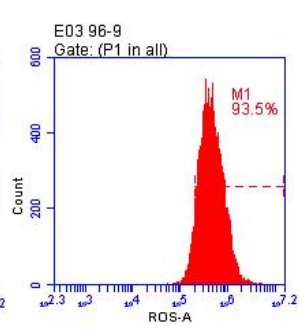

$\mathbf{F}$
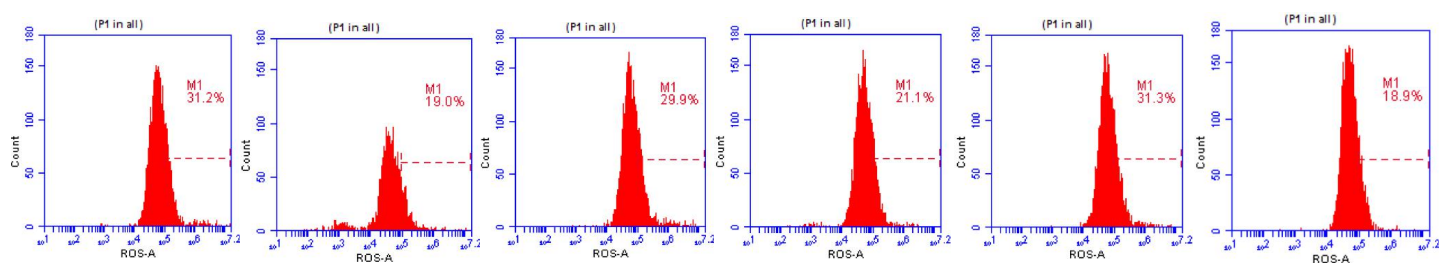

Figure 4. Effects of high-glucose combined with or without insulin on ROS production in GH3 cells. (A-C) ROS levels in $17.49 \mathrm{mM}$ glucose-cultured GH3 cells after incubation with or without $10^{-7}, 10^{-8}$, or $10^{-9} \mathrm{M}$ insulin for $24 \mathrm{~h}$ (A), $48 \mathrm{~h}$ (B), or $72 \mathrm{~h}$ (C). (D-F) ROS levels in $17.49 \mathrm{mM}$ or $30 \mathrm{mM}$ glucose-cultured GH3 cells after incubation for $24 \mathrm{~h}(\mathrm{D}), 48 \mathrm{~h}(\mathrm{E})$, or $72 \mathrm{~h}(\mathrm{~F})$.

\section{High-level glucose with or without insulin mitigates apoptosis}

Following the decline of ROS levels, it was anticipated that ROS-induced apoptosis should be accordingly mitigated. As illustrated in Figure 5A-5C, it was shown that the total apoptotic cell percentages are extremely lower in $10^{-7}, 10^{-8}$, or $10^{-9} \mathrm{M}$ insulin-treated GH3 cells than those in untreated GH3 cells after incubation for 24, 48, or $72 \mathrm{~h}$ in the medium containing $17.94 \mathrm{mM}$ glucose. For example, apoptotic cell 
percentages in $10^{-7}, 10^{-8}$, or $10^{-9} \mathrm{M}$ insulin-treated $\mathrm{GH} 3$ cells for $24 \mathrm{~h}$ are $20.5 \%$, $20.0 \%$, or $26.1 \%$, whereas those in untreated $\mathrm{GH} 3$ cells are $32.6 \%$, further addressing insulin enables compromise of ROS-driven apoptosis.

In similar, the late-phase apoptotic cell percentages after incubation for $24 \mathrm{~h}$ are almost equal $(5.5 \%$ or $6.1 \%)$ in those cells treated with $17.94 \mathrm{mM}$ or $30 \mathrm{mM}$ glucose but without insulin (Figure 5D-5F). These results indicated that a high-level glucose but insulin-free medium weakens apoptosis induction, probably due to limited glucose uptake without insulin even under the glucose-rich environment.

A

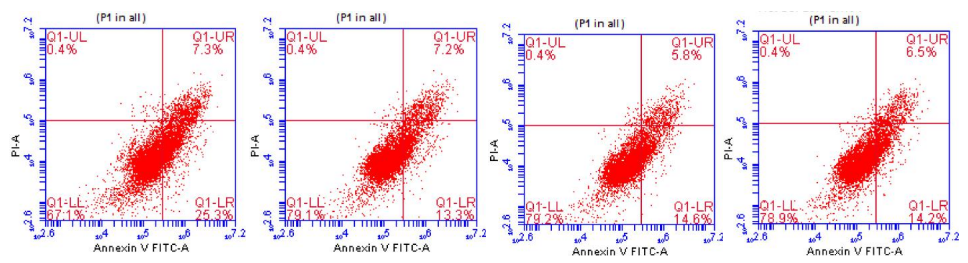

B

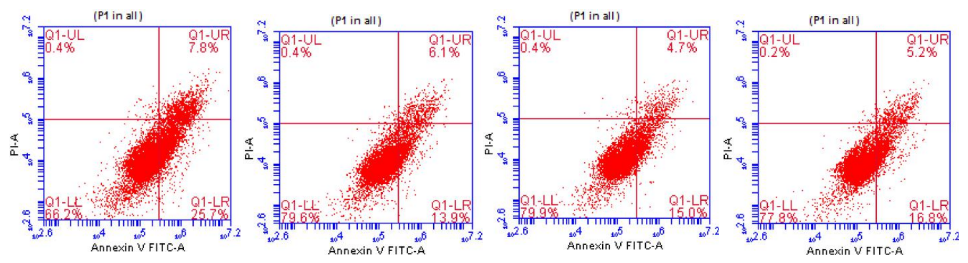

C

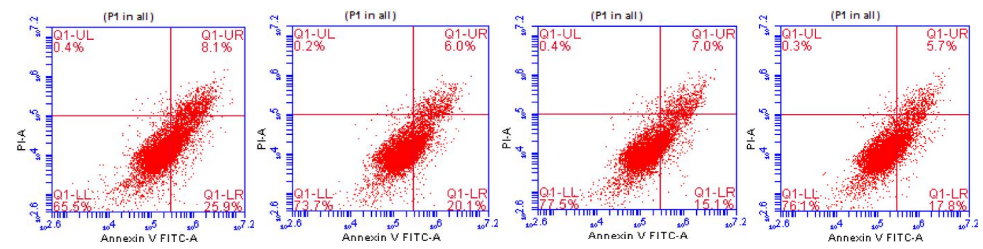

D
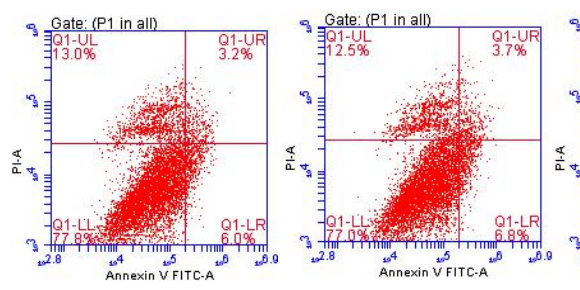

E

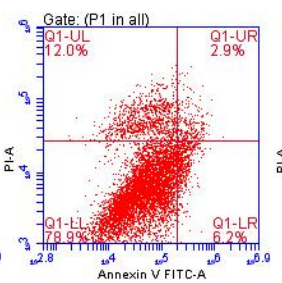

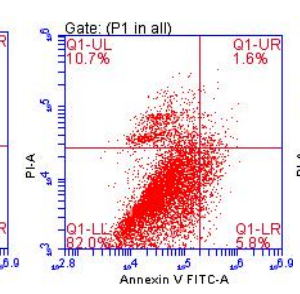

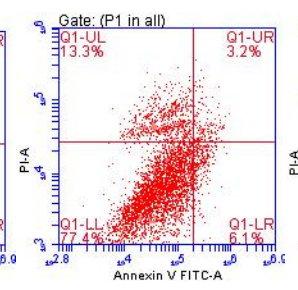

$\mathbf{F}$

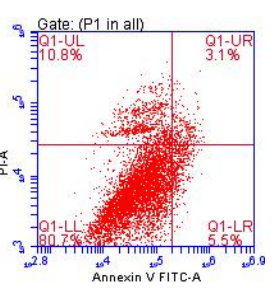

Figure 5. Effects of high-glucose combined with or without insulin on apoptotic induction in GH3 cells. (A-C) Apoptotic cell percentages in $17.49 \mathrm{mM}$ glucose-cultured GH3 cells after incubation with or without $10^{-7}, 10^{-8}$, or $10^{-9} \mathrm{M}$ insulin for $24 \mathrm{~h}(\mathrm{~A}), 48 \mathrm{~h}(\mathrm{~B})$, or $72 \mathrm{~h}(\mathrm{C})$. (D-F) Apoptotic cell percentages in $17.49 \mathrm{mM}$ or $30 \mathrm{mM}$ glucose-cultured GH3 cells incubated for $24 \mathrm{~h}(\mathrm{D}), 48 \mathrm{~h}(\mathrm{E})$, or $72 \mathrm{~h}(\mathrm{~F})$.

\section{Knockdown of NOS2 exhibits anti-tumor and anti-oxidation effects}

To explore the possible mechanism underlying how can cellular starvation exert 
anti-tumor effects, we assumed cellular starvation might compromise the cell division responsible PI3K-Akt-mTOR signaling by downregulating insulin growth factor 1 (IGF-1). Thus, we quantified the expression level of $I G F-1$ mRNA and IGF-1 in GH3 cells. As incubated with $10^{-7} \mathrm{M}$ insulin for 24,48 , and $72 \mathrm{~h}$, with $10^{-8} \mathrm{M}$ insulin for 24 and $48 \mathrm{~h}$, or with $10^{-9} \mathrm{M}$ insulin for 24 and $48 \mathrm{~h}, I G F-1 \mathrm{mRNA}$ levels (Figure 6A) and IGF-1 levels (Figure 6B) are significantly lower than those in untreated GH3 cells. Intriguingly, GH3 cells even overexpress $I G F$ mRNA and IGF after incubation with $10^{-9} \mathrm{M}$ insulin for $48 \mathrm{~h}$ and $72 \mathrm{~h}$. It was unable to be well explained at this moment, but it might be possible that compensation of an extremely low insulin level by IGF-1 overexpression. Because tumor cells are de-differentiated cells where genes are non-specifically expressed, IGF-1 was able to be detected in GH3 cells even though the pituitary gland is not an IGF-1-secreting organ.

To further explore the alternative mechanism behind cellular starvation exerting anti-tumor effects, we proposed CR-like anti-inflammatory responses might emerge as pivotal steps toward anti-tumor, which should downregulate NOS2-encoded inducible nitric oxide synthase (iNOS). Therefore, we investigated the putative relevance of NOS2 knockdown with anti-oxidation and anti-tumor activity. By constructing NOS2-targeted small interfering RNA (siRNA) vectors and infecting them into breast cancer cells, we obtained the stable NOS2 expression inhibitory cell line HCC1937 (psiN3) with the best interfering effect. From Figure 6C, it was evident that $N O S 2 /$ iNOS downregulation is synchronous to upregulation of NOS3-encoded endothelial NOS (eNOS), accompanying with downregulation of the oncogene CD1 and upregulation of the tumor suppressor gene $p 21$. Furthermore, NOS2 knockdown also upregulate the common anti-oxidation responsive genes, including the transcription factor Forkhead box $\mathrm{O} 3$ (FOXO3a) that upregulates antioxidant enzymes, $H O-1$ encoding heme oxygenase 1, EPO encoding erythropoietin, and $V E G F$ encoding vascular endothelial growth factor (Figure 6D).

These results indicated NOS2 knockdown can replicate CR-mediated anti-oxidant and anti-tumor effects, in which CDI downregulation was seen in CR-like cellular starvation, and upregulation of anti-oxidation responsible genes was also consistent with the outcome of compromised oxidative stress and ROS-induced apoptosis occurring in CR-like cellular starvation. 
A

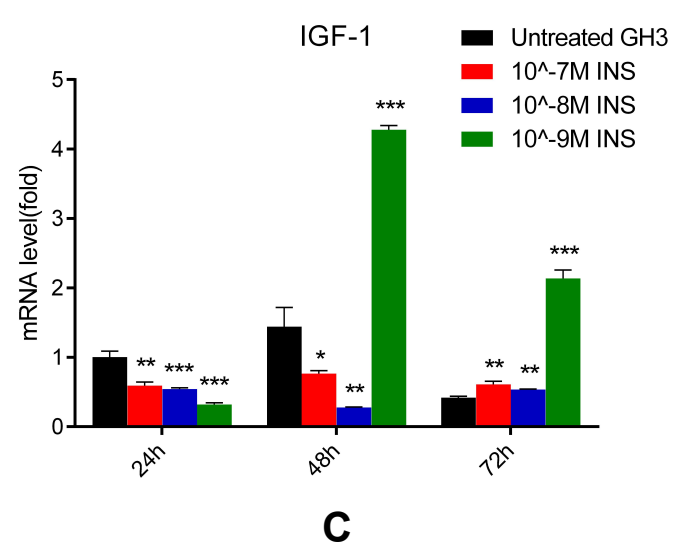

C

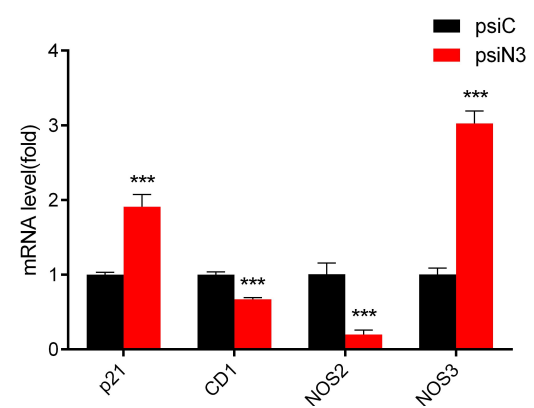

B

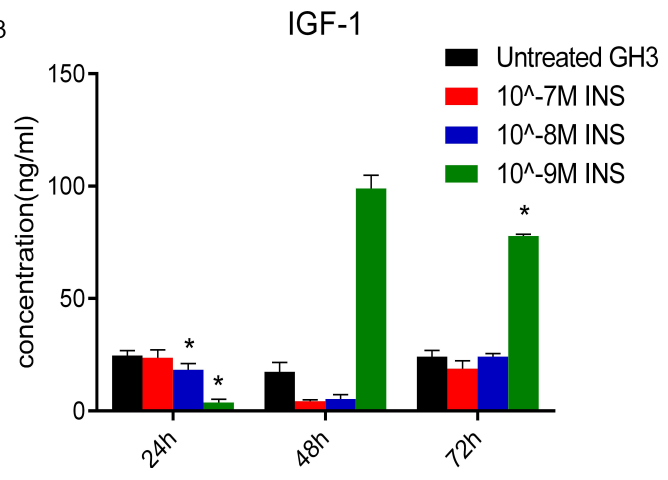

D

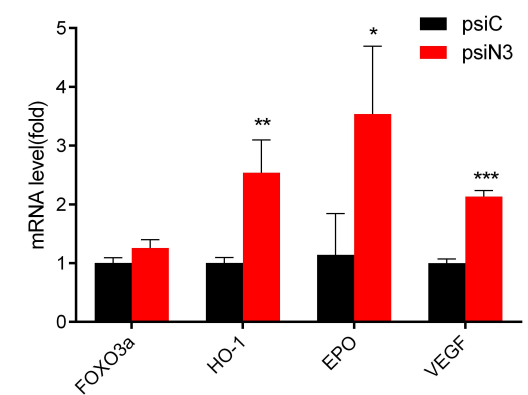

Figure 6. Effects of exogenous insulin on IGF-1 expression in GH3 cells grown in a high-glucose medium ( $A$ and $B$ ) and effects of NOS2 knockdown on the expression of anti-tumor and anti-oxidation responsible genes (C and D). (A) Fold changes of IGF-1 mRNA. (B) Concentrations of IGF-1. Glucose concentration is $17.49 \mathrm{mM}$. Insulin dose is $10^{-7}, 10^{-8}$, or $10^{-9} \mathrm{M}$, and incubation duration is 24,48 , or 72 h. INS: insulin. *: Significant difference from untreated GH3 cells $(p<0.05, n=10)$. **: Very significant difference from untreated GH3 cells $(p<0.01)$. ***: Very very significant difference from untreated $\mathrm{GH} 3$ cells $(p<0.001, n=10)$. (C) Fold changes of $p 21, C D 1, N O S 2$, and NOS3 mRNAs in HCC1937 (psiN3) cells. (D) Fold changes of FOXO3a, HO-1, EPO, and VEGF mRNAs HCC1937 (psiN3) cells. *: Significant difference from HCC1937 (psiN3) cells $(p<0.05, n=6)$ **: Very significant difference from HCC1937 (psiN3) cells $(p<0.01, n=6)$. ***: Very very significant difference from HCC1937 (psiN3) cells $(p<0.001, n=6)$.

\section{Discussion}

Upon incubation with different doses of insulin for different duration, GH3 cells exhibit growth inhibition with $I G F-1$ downregulation, addressing insulin does not exert a tumor-promoting effect in a CR-resembling manner [21, 22]. Although IGF-1 is typically secreted by the liver upon accepting GH-conveying signals, it can also non-specifically expressed in tumor tissues with a de-differential feature. For example, melanoma-initiating cells can produce IGF-1 [23], and multiple myoloma cells can also generate IGF-1 [24]. Therefore, it could be acceptable that $I G F-1$ downregulation can mimic metformin to repress tumor cell propagation because of impeded PI3K-Akt-mTOR signaling. An earlier study indicated metformin inactivates mTOR 
to inhibit breast cancer cell growth [25]. Clinically, metformin was observed to decrease the cancer rate for $25-40 \%$ via inactivating mTOR [26].

Whether insulin or high-glucose downregulates $I G F-1$ remains unanswered at this moment, but we suppose herein that downregulation of $I G F-1$ might be attributed to an intracellular low glucose milieu in tumor cells with insulin resistance. To replicate hyperglycemia seen in T1DM/T2DM, we cultured GH3 cells in the medium containing high-glucose $(17.49 \mathrm{mM})$ or higher-glucose $(30 \mathrm{mM})$ in combination with or without $10^{-9}-10^{-7} \mathrm{M}$ insulin. In other researches, 10,15 , or $20 \mathrm{mM}$ glucose as well as $10^{-7} \mathrm{M}$ insulin were separately exploited to induce insulin resistance in adipocytes and hepatoma cells [17, 18]. Regardless of insulin presence or absence, insulin resistance should be induced in GH3 cells by $17.49 \mathrm{mM}$ or $30 \mathrm{mM}$ glucose that resembles hyperglycemia. A high rate of hyperglycemia has been proven to be associated with inhibitors targeting IGF-1 receptor, which mediates a deleterious metabolic effect by decreasing insulin secretion and increasing insulin resistance in peripheral tissues [27]. Furthermore, a case of "pseudoacromegaly" has been reported to exhibit insulin resistance accompanying with a low IGF-1 level [28].

Laron syndrome (dwarfism), a genetic disease arisen from a mutant GH receptor gene, confers the low risks of DM and cancer [29]. The patients with Laron syndrome are characterized by a high level of GH (GH resistance) and a low level of IGF-1 [30]. Interestingly, we also observed a slow rate of cell growth is synchronous to a low level of IGF-1 in a high-glucose medium supplemented with insulin, suggesting an association of low-level IGF-1 with low-rate cell division [31]. Considering a dual downregulation of $I G F-1$ and $N F-\kappa B$ by CR [21], and also because of NF- $\kappa \mathrm{B}$ upregulate NOS2/iNOS, we postulated here that CR should exert anti-tumor effects via downregulating NOS2/iNOS. Indeed, we confirmed in the present study that NOS2 knockdown not only decreases NOS2/iNOS and increases NOS3/eNOS, but also downregulates $C D 1$ and upregulates $p 21$, suggesting CR-like anti-tumor activity is mediated by turning off iNOS and turning on eNOS.

On the other hand, we noticed decrease in ROS and reduction in apoptosis of GH3 cells grown in a high-glucose medium supplemented with insulin, which was also observed in CR [32]. In our previous work, CR in yeast and mice was also found to diminish ROS burst, compromise telomere shortening, and promote lifespan extension $[33,34]$. It is well-known that resveratrol is an activator of SIRT, metformin is an activator of AMPK, and CR activates AMPK, SIRT1, and PGC-1 $\alpha[35,36]$. PGC-1 $\alpha$ 
in turn promotes mitochondrial biogenesis for multiple beneficial effects [37]. Therefore, it was understood that CR-like anti-oxidant effects should mitigate ROS burst and attenuate ROS-induced apoptosis. In the experimental confirmation of CR-like anti-oxidant effects by NOS2 knockdown, we noticed the significant upregulation of a series of anti-oxidation responsible genes. FOXO3a serves as a tumor suppressor for protection from oxidative stress by upregulating antioxidant enzymes such as catalase and superoxide dismutase (SOD) [38]. HO-1 reduces oxidative stress by degrading the pro-oxidant heme [39]. EPO and VEGF promote erythropoiesis and angiogenesis to attenuate anemia and hypoxia [40, 41].

Intriguingly, we found treatment of GH3 cells by high-level glucose without insulin even gives rise to the similar consequence as treatment of GH3 cells by high-level glucose with insulin. We assumed the high-level glucose might downregulate glucose transporters and decreases glucose intake. A previous work showed sustained hyperglycemia in vitro downregulates GLUT1 [16]. However, an in vitro hyperglycemic environment was demonstrated to promote tumor progression by upregulation of GLUT1 and GLUT3 [42]. A five-year clinic observation also indicated hyperglycemia is highly related to aggravation of rectal tumors [43]. These contradictory outcomes would be reasonably interpreted by discriminating insulin sensitivity from insulin resistance. On one hand, insulin deficiency-caused hyperglycemia in T1DM with insulin sensitivity might show cancer promotion once insulin was administered and glucose uptake accelerated, which is also the reason why insulin is effective for hypoglycemia in T1MD patients. On the other hand, insulin receptors (IR) dysfunction-originated hyperglycemia in T2MD with insulin resistance might exhibit cancer prohibition regardless insulin was administered or not, which is also the reason why insulin is ineffective and metformin was effectively used in T2MD patients.

Alternatively, the above inconsistent data could be also explained by inactivation of PTEN due to the germ-line gene mutation [44] or suppression of PTEN transcription by NF- $\kappa B$ directly binding to the PTEN promoter under a pro-inflammatory circumstance [45]. This is because PI3K-activated glucose transport into cells via GLUT is antagonized by PTEN [46]. When PI3K is over-activated, cells prone to intake more glucose for anaerobic respiration (Warburg effects), which accounts for 10 to 20 -fold increases of metabolic activity that predisposes mutagenesis [47]. These results implied PTEN should be in deficiency under the inflammation niches and 
hence some T1MD/T2MD patients might exhibit enhanced PI3K-Akt-mTOR signaling toward higher cancer risks.

Conclusively, insulin neither enhances pituitary adenoma cell propagation nor upregulates $C D 1$ and $A F P$ expression in $17.49 \mathrm{mM}$ or $30 \mathrm{mM}$ glucose medium supplemented with or without $10^{-7}-10^{-9} \mathrm{M}$ insulin during 24-72 $\mathrm{h}$ of incubation. Mechanically, a high-glucose environment that induces insulin resistance and blocks glucose transport can mimic CR to exert anti-tumor effects by dually downregulating $I G F-1$ and NOS2 expression. Whether insulin use would increase the cancer risk in the subjects with the insulin sensitive early-phase DM merits further clinical elucidation.

\section{Materials and Methods}

\section{Cell culture and insulin incubation}

The rat pituitary adenoma cell line GH3 was cultured in $25 \mathrm{~cm}^{2}$ cultural vessels and placed in a humidified incubator at $37^{\circ} \mathrm{C}$ with an atmosphere of $5 \% \mathrm{CO}_{2}$ and $95 \% \mathrm{O}_{2}$. Unless indicated, cells were cultivated in a $17.49 \mathrm{mM} D$-glucose-containing DMEM/F12 liquid medium (Hyclone, Cat. No. SH30023.01B) supplemented with heat-inactivated fetal bovine serum (Gibco, Cat. No. 10099-141), $100 \mathrm{U} / \mathrm{ml}$ penicillin, and $100 \mathrm{~g} / \mathrm{ml}$ streptomycin. Alternatively, cell were cultivated in a $30 \mathrm{mM}$ $D$-glucose-containing DMEM liquid medium (Hyclone, Cat. No. SH30022.01B, containing $24.51 \mathrm{mM} D$-glucose) supplemented with $5.49 \mathrm{mM} D$-glucose and heat-inactivated fetal calf serum (Gibco, Cat. No. 10099-141), $100 \mathrm{U} / \mathrm{ml}$ penicillin, and $100 \mathrm{~g} / \mathrm{ml}$ streptomycin was also included. Upon centrifuged at $1000 \mathrm{r} / \mathrm{min}$ for 5 min, cell suspensions were transferred into 6-well culture plates for incubation in a $17.49 \mathrm{mM}$ glucose-containing DMEM/F12 liquid medium with human insulin (Sigma, Cat. No. I3536) in a dose of $10^{-7}, 10^{-8}$, or $10^{-9} \mathrm{M}$ for 24,48 , or $72 \mathrm{~h}$, or in a $30 \mathrm{mM}$ glucose-containing DMEM liquid medium for 24,48 , or $72 \mathrm{~h}$. After completion of culture, cells were pooled by centrifugation for further analysis.

\section{qPCR}

RNA isolation, quality control, electrophoresis, reverse transcription, and quantification were performed using Agilent Stratagene MX3000P in a PCR reaction $\left(92^{\circ} \mathrm{C} 2 \mathrm{~min}, 94^{\circ} \mathrm{C} 20 \mathrm{sec}, 58^{\circ} \mathrm{C} 20 \mathrm{sec}, 72^{\circ} \mathrm{C} 20 \mathrm{sec}, 40\right.$ cycles) by following forward $(\mathrm{F})$ and reverse $(\mathrm{R})$ primers designed for the reference gene $\beta$-actin and all target 
genes.

\begin{tabular}{ll}
\hline Gene & Primer \\
\hline$\beta$-actin $\mathrm{F}$ & CATTGCTGACAGGATGCAGA \\
$\beta$-actin $\mathrm{R}$ & CTGCTGGAAGGTGGACAGTGA \\
GH $\mathrm{F}$ & CCTACATTCCCGAGGACAGC \\
GH $\mathrm{R}$ & GCAGCGAGAAGCGAAGCAA \\
$I G F-l \mathrm{~F}$ & CCTTCACTCTGTACCGCATCG \\
$I G F-l \mathrm{R}$ & GGGTCTTGGCTCCCAGGTCA \\
$C D l \mathrm{~F}$ & GTCCCTGGAGCCCTTGAAGAA \\
$C D l \mathrm{R}$ & GCCGGATAGAGTTGTCAGTGTAG \\
$A F P \mathrm{~F}$ & CCCTCATCCTCCTGCTACATT \\
$A F P \mathrm{R}$ & CGGAACAAACTGGGTAAAGGT \\
\hline
\end{tabular}

The copy numbers of amplified genes were estimated by $2^{-\Delta \mathrm{CT}}$, in which $\Delta \mathrm{CT}=$ (target gene (treatment group) / target gene (control group)) / (housekeeping gene (treatment group) / house-keeping gene (control group)). The raw qPCR data were normalized by the copy numbers of the reference gene $\beta$-actin, and the fold changes of each target gene were calculated by comparing the $2^{-\Delta \mathrm{CT}}$ value of a treatment sample with that of a control sample.

\section{WB and enzyme-linked immunosorbent assay (ELISA)}

The reference protein GAPDH and all tested antigen proteins were immunoquantified according to manufacture's manuals. Anti-CD1 antibody (H-295, Cat. No. sc-753) and anti-AFP antibody (C-19, Cat. No. sc-8108) were purchased from Santa Cruz Biotechnology Inc., USA. The ELISA Kits for rat GH (Cat. No. F3997-A) and rat IGF-1 (Cat. No. F8278-A) were purchased from Shanghai Kexing Biotechnology Ltd Co., China.

\section{Dynamic cell growth monitoring}

After staining cells with CCK-8, absorbance at the wave length of $450 \mathrm{~nm}\left(\mathrm{~A}_{450}\right)$ was measured using a microplate reader (Thermo Fisher Scientific, Multiscan MK3) to monitor dynamic cell growth.

\section{ROS and apoptosis analysis}

ROS Assay Kit (S0033) was obtained from Beyotime Institute of Biotechnology, China. Annexin V/PI Apoptosis Kit (AP101) and Cell Cycle Staining Kit (CCS012) were supplied by Hangzhou MultiScience (Lianke) Biotech Co., Ltd., China. ROS and apoptosis were measured by a flow cytometer (BD, FACS Calibur) using corresponding reagent kits and based on manufacturer's instructions. 


\section{NOS2 knockdown by short-hairpin RNA interference}

By inserting one of three candidate siRNA fragments, siRNA-NOS2-1/2/3 (abbrev. siN1/2/3, interfering with one of three selected NOS 2 target sequences into the expression plasmid vector pSUPERretro, three recombinant siRNA-NOS2-expressing constructs, pSUPERretro-siN1/2/3 (abbrev. psiN1/2/3), were obtained. After transiently infecting one of them into HCC1937 cells, NOS2 mRNA and iNOS levels were quantified in HCC1937 (psiN1/2/3) cells. Among the transformed cells, NC (psiN3) cells with the lowest NOS2 mRNA and iNOS levels were obtained. So psiN3 was chosen to stably transfect HCC1937 cells for establishing a stable cell line HCC1937 (psiN3).

\section{Statistical analysis}

The software SPSS 22.0 was employed to analyze data, and the software GraphPad Prism 5.0 was employed to plot graphs. The Independent Simple Test was used to compare all groups, but the Kruskal-Wallis Test followed by Nemenyi test was used when the data distribution is skewed. The significance level ( $p$ value) was set at $<0.05$ $(*),<0.01(* *)$, and $<0.001(* * *)$.

\section{Acknowledgments}

We thank our colleagues in Tropical Medicine Institute of Guangzhou University of Chinese Medicine. This work was supported by the National Natural Science Foundation of China (No. 81273620 to Q.P.Zeng and No. 81673861 to C.Q. Li) and by the High-Level University Construction Foundation of Guangdong Province of China (No. 2050205).

\section{Author Contributions}

Conceptualization: QPZ and CQL. Data curation: QPZ and TL. Formal analysis: TL; XAH. Funding acquisition: QPZ; CQL; XHL. Investigation: TL; YPC; LLT. Methodology: TL; JDZ. Project administration: SQH; QX. Resources: QX; XAH. Software: XAH. Supervision: QX. Validation: QPZ; QX. Visualization: QPZ; TL. Writing original draft: QPZ; CQL. Writing review \& editing: QPZ; CQL; TL.

\section{References}

1. International Diabetes Federation. IDF diabetes atlas. $7^{\text {th }}$ ed. 2015. p. 9 
2. World Health Organization. The top 10 causes of death Fact sheet $\mathrm{N}^{\circ} 310$. Oct 2013.

3. Waugh $\mathrm{N}$ et al. (2010) Newer agents for blood glucose control in type 2 diabetes: systematic review and economic evaluation. Health Technol Assess (Winchester, England). 14: 1-248. PMID:20646668

4. Hemkens LG, Grouven U, Bender R, Günster C, Gutschmidt S, Selke GW, et al.(2009) Risk of malignancies in patients with diabetes with human insulin or insulin analogues: a cohort study. Diabetologia. 52: 1732-1744. PMID:19565214

5. Jonasson JM, Ljung R, Talbäck M, Haglund B, Gudbjörnsdòttir S, Steineck G (2009) Insulin glargine use and short-term incidence of malignancies: a population-based follow-up study in Sweden. Diabetologia 52: 1745-1754. PMID:19588120

6. Colhoun HM, SDRN Epidemiology Group (2009) Use of insulin glargine and cancer incidence in Scotland: a study from the Scottish Diabetes Research Network Epidemiology Group. Diabetologia 52: 1755-1765. PMID:19603149

7. Currie CJ, Poole CD , Gale EA (2009) The influence of glucose-lowering therapies on cancer risk in type 2 diabetes. Diabetologia 52: 1766-1777. PMID:19572116

8. Tang X, Yang L, He Z, Liu J. (2012) Insulin glargine and cancer risk in patients with diabetes: a meta-analysis. PLoS One 7: e51814. doi: 10.1371/journal.pone.0051814. PMID:23284776

9. Rendell M, Atkurk HK, Tella SH (2013) Glargine safety, diabetes and cancer. Exp Opin Drug Saf 12: 247-263. PMID:2339444

10. Tseng CH (2015) Prolonged use of human insulin increase breast cancer risk in Taiwanese women with type 2 diabetes. BMC Cancer 15: 846. PMID:26537234

11. Shao Y, Cheng S, Hou J, Zuo Y, Zheng W, Xia M,et al. (2016) Insulin is an important risk factor of endometrial cancer among premenopausal women: a case-control study in China. Tumour Biol 37: 4721-4726. PMID:26511973

12. Zeng QP (2015) Artemisinin and nitric oxide: mechanisms and implications in disease and health, Springer

13. Asa SL, Ezzat S (2009) The pathogenesis of pituitary tumors. Ann Rev Pathol 4: 97-126. PMID:19400692

14. Monsalves E, Juraschka K, Tateno T, Agnihotri S, Asa SL, Ezzat S, et al. (2014) The $\mathrm{PI} 3 \mathrm{~K} / \mathrm{AKT} / \mathrm{mTOR}$ pathway in the pathophysiology and treatment of pituitary adenomas. Endocr Relat Cancer 21: R331-R344. PMID:25052915

15. Musat M, Korbonits M, Kola B, Borboli N, Hanson MR, Nanzer AM, et al. (2005) Enhanced protein kinase B/Akt signalling in pituitary tumours. Endocrine-Related Cancer 12: 423-433. PMID:15947113

16. Hahn T, Barth S, Weiss U, Mosgoeller W, Desoye G (1998) Sustained hyperglycemia in vitro down-regulates the GLUT1 glucose transport system of cultured human term placental trophoblast: a mechanism to protect fetal development? FASEB J.12:1221-1231.

PMID:9737725 
17. Liu HX. (2001) The molecular mechanism of high glucose-induced insulin resistance in 3T3-L1 adipocytes. Hunan Yi Ke Da Xue Xue Bao 26: 294-296. PMID:12536716

18. Li CG, Ning G, Chen JL. (1999) Establishing and identifying insulin resistant HepG2 cell line. Chinese J Diabetes 7: 198-200

19. Mercken EM, Crosby SD, Lamming DW, JeBailey L, Krzysik-Walker S, Villareal D. et al. (2013) Calorie restriction in humans inhibits the PI3K/AKT pathway and induces a younger transcription profile. Aging Cell 12: 645-651. PMID:23601134

20. Lamming DW. (2014) Diminished mTOR signaling: a common mode of action for endocrine longevity factors. Springerplus 3: 735. PMID: 25674466

21. Jung KJ, Lee EK, Kim JY, Zou Y, Sung B, Heo HS, Kim MK, Lee J, Kim ND, Yu BP, Chung HY (2009) Effect of short term calorie restriction on pro-inflammatory NF-kB and AP-1 in aged rat kidney. Inflamm Res 58:143-150. PMID:19199090

22. Harvey AE, Lashinger LM, Otto G, Nunez NP, Hursting SD (2013) Decreased systemic IGF-1 in response to calorie restriction modulates murine tumor cell growth, nuclear factor- $\mathrm{\kappa}$ activation, and inflammation-related gene expression. Mol Carcinog 52: 997-1006. PMID: 22778026

23. Le Coz V, Zhu C, Devocelle A, Vazquez A, Boucheix C, Azzi S, Gallerne C, Eid P, Lecourt S, Giron-Michel J (2016) IGF-1 contributes to the expansion of melanoma-initiating cells through an epithelial-mesenchymal transition process. Oncotarget 7:82511-82527. PMID:27764776

24. Li Y, Yang T, Li J, Hao HL, Wang SY, Yang J, Luo JM (2016) Inhibition of multiple myeloma cell proliferation by ginsenoside Rg3 via reduction in the secretion of IGF-1. Mol Med Rep 14:2222-2230. PMID:27430248

25. Zakikhani M, Dowling R, Fantus IG, Sonenberg N, Pollak M (2006) Metformin is an AMP-kinase dependent growth inhibitor for breast cancer cells. Cancer Res 66: 10269-10273. PMID: 17062558

26. Taubes G (2012) Cancer prevention with a diabetes pill? Science 335: 29. PMID:22223788

27. Shlomai G, Neel B, LeRoith D, Gallagher EJ.(2016) Type 2 diabetes mellitus and cancer: the role of pharmacotherapy. J Clin Oncol 34:4261-4269. PMID:27903154

28. Sam AH, Tan T, Meeran K (2011) Insulin-mediated "pseudoacromegaly". Hormones (Athens) 10:156-161. PMID:21724541

29. Leslie M (2011) Growth defects blocks cancer and diabetes. Science 331: 837. doi: 10.1126/science.331.6019.837. PMID:21330503

30. Bartke A, Sun LY, Longo V (2013) Somatotropic signaling: trade-offs between growth, reproductive development, and longevity. Physiol Rev 93:571-598. PMID:23589828

31. Pollak M (2008) Insulin and insulin-like growth factor signaling in neoplasia. Nat Rev 8 : 915-928. PMID:19029956

32. Rains JL, Jain SK (2011) Oxidative stress, insulin signaling and diabetes. Free Rad Biol Med 


\section{0: 567-575. PMID:21163346}

33. Wang DT, Wu M, Li SM, Gao Q, Zeng QP (2015) Artemisinin mimics calorie restriction to extend yeast lifespan via a dual-phase mode: a conclusion drawn from global transcriptome profiling. Sci China Life Sci 58: 451-465. PMID:25682392

34. Wang DT, He J, Wu M, Li SM, Gao Q, Zeng QP (2015) Artemisinin mimics calorie restriction to trigger mitochondrial biogenesis and compromise telomere shortening in mice. Peer J 3: e822. PMID:25780774

35. Coschigano KT, Holland AN, Riders ME, List EO, Flyvbjerg A, Kopchick JJ (2003) Deletion, but not antagonism, of the mouse growth hormone receptor results in severely decreased body weights, insulin, and insulin-like growth factor 1 levels and increased life span. Endocrinology 144: 3799-3810. PMID:1293365

36. Bhullar KS, Hubbard BP (2015) Lifespan and healthspan extension by resveratrol. Biochim Biophys Acta 1852:1209-1218. PMID:256408

37. Martin-Montalvo A, Mercken EM, Mitchell SJ, Palacios HH, Mote PL, Scheibye-Knudsen M, et al. (2013) Metformin improves healthspan and lifespan in mice. Nat Comm 4:Article 2192. doi: 10.1038/ncomms3192. PMID:23900241

38. Myatt SS, Lam EW (2007) The emerging roles of forkhead box (Fox) proteins in cancer. Nat Rev Cancer. 7: 847-859. PMID:17943136

39. Ozono R (2006) New biotechnological methods to reduce oxidative stress in the cardiovascular system: focusing on the Bach1/heme oxygenase-1 pathway. Curr pharmaceut biotechnol 7: 87-93. PMID:1672942

40. Liu S, Ren J, Hong Z, Yan D, Gu G, Han G, Wang G, Ren H, Chen J, Li J (2013). Efficacy of erythropoietin combined with enteral nutrition for the treatment of anemia in Crohn's disease: a prospective cohort study. Nutr Clin Pract 28: 120-127. PMID:23064018

41. Palmer BF, Clegg DJ (2014) Oxygen sensing and metabolic homeostasis. Mol Cell Endocrinol 397: 51-57. PMID:25132648

42. Ryu TY, Park J, Scherer PE (2014) Hyperglycemia as a risk factor for cancer progression. Diabetes Metab J 38: 330-336. PMID:25349819

43. Cui G, Zhang T, Ren F, Feng WM, Yao Y, Cui J, et al. (2015) High blood glucose levels correlate with tumor malignancy in colorectal cancer patients. Med Sci Mon 21:3825-3833. PMID:26644185

44. Podsypanina K, Ellenson LH. (1999) Mutation of PTEN/Mmac1 in mice causes neoplasia in multiple organ systems. Proc Natl Acad Sci USA 96:1563-1568. PMID:9990064

45. Palumbo T1, Faucz FR, Azevedo M, Xekouki P, Iliopoulos D, Stratakis CA. (2013) Functional screen analysis reveals miR-26b and miR-128 as central regulators of pituitary somatomammotrophic tumor growth through activation of the PTEN-AKT pathway. Oncogene 32:1651-1659. PMID: 22614013

46. Barbieri M, Bonafè M, Franceschi C, Paolisso G (2003) Insulin/IGF-I-signaling pathway: an 

available under aCC-BY-NC 4.0 International license.

evolutionarily conserved mechanism of longevity from yeast to humans. Am J Physiol

Endocrinol Metab 285(5):E1064-1071. PMID:14534077

47. Taubes G (2012) Cancer prevention with a diabetes pill? Science 335:29. PMID:22223788 